\title{
Postherpetic neuralgia: Review of treatment modalities
}

\author{
Philip SL Chan, Alexander J Clark MD FRCPC
}

\section{PSL Chan, AJ Clark. \\ Postherpetic neuralgia: Review of treatment modalities. Pain Res Manage 2000;5(1):69-74.}

BACKGROUND: Varicella zoster virus (VZV) is the etiological agent for both varicella (chickenpox) and herpes zoster (HZ) (shingles). HZ results from the reactivation of VZV acquired during childhood. Postherpetic neuralgia (PHN) is the most common complication of $\mathrm{HZ}$ infection in immunocompetent patients. There is no universally accepted definition of PHN. While the mechanisms producing pain associated with PHN are not fully understood, peripheral and central processes are thought to be important. METHODS: The literature on the pathophysiology and the treatment of postherpetic neuralgia was reviewed for the past 30 years by using Index Medicus.

CONCLUSIONS: Many modalities to treat PHN are available; none of them are very effective. The most commonly used modalities are tricyclic antidepressants, anticonvulsants, opioid analgesics, topical medications, physical modalities such as acupuncture and transcutaneous nerve stimulation, and nerve blocks. The tricyclic antidepressants have the most evidence supporting their role in treating PHN, although only half of the patients with PHN benefit. Recent studies support the use of opioid analgesics in PHN. There is a growing body of evidence in support of the use of gabapentin for PHN. Physical modalities and topical medications are probably most useful as adjuncts to centrally acting agents, not as a primary treatment modality. Injections (nerve blocks) are effective in relieving PHN anecdotally, although there are no controlled clinical trials showing efficacy.

Key Words: Chronic pain; Neuropathic pain; Postherpetic neuralgia

\section{Névralgie post-zostérienne : Revue des modalités thérapeutiques}

HISTORIQUE : Le virus varicelle-zona ou VZV est l'agent étiologique de la varicelle et du zona. Le zona résulte d'une réactivation du VZV acquis durant l'enfance. La névralgie post-zostérienne est la plus fréquente complication du zona chez les patients immunocompétents. Il n'y a aucune définition universellement acceptée de la névralgie post-zostérienne. Si les mécanismes responsables de la douleur qu'elle engendre sont encore mal élucidés, des processus périphériques et centraux joueraient un rôle important.

MÉTHODES : On a passé en revue la littérature sur la physiopathologie et le traitement de la névralgie post-zostérienne pendant les 30 dernières années au moyen de l'index Medicus.

CONCLUSION : De nombreuses modalités existent pour traiter la névralgie post-zostérienne. Aucune n'est très efficace. Les modalités les plus couramment utilisées sont les antidépresseurs tricycliques, les anticonvulsivants, les opiacés, les médicaments topiques, les modalités physiques comme l'acupuncture et la stimulation nerveuse transcutanée et les blocs nerveux. Le rôle des antidépresseurs tricycliques repose sur un plus grand nombre preuves pour ce qui est du traitement de la névralgie post-zostérienne, bien que la moitié seulement des patients semblent en tirer profit. De récentes études appuient l'utilisation des opiacés dans la névralgie post-zostérienne et les preuves de l'utilité de la gabapentine s'accumulent. Les modalités physiques et les médicaments topiques sont probablement plus utiles comme traitements d'appoint aux agents à action centrale et non pas comme modalité thérapeutique de première intention. Les injections (blocs nerveux), sont efficaces, selon certains rapports anecdotiques mais aucun essai clinique contrôlé n'en a prouvé l'efficacité. 
$\mathrm{V}$ aricella zoster virus (VZV) is the etiological agent for two clinical diseases: varicella (chickenpox) and herpes zoster (HZ) (shingles). Primarily a disease of childhood, varicella is passed from child to child by direct contact with infected lesions or by inhalation of airborne droplets (1). HZ results from the reactivation of VZV acquired during childhood that had been dormant in sensory ganglia (2).

Donahue et al (3) estimated the incidence of HZ, based on the patient population of a New England Health Maintenance Organization, to be 215 per 100,000 person-years. Incidence rates increased with age, peaking at 1424 cases per 100,000 person-years among persons at least 75 years old. One of few studies (4) on the incidence of HZ, a community-based study of residents in Rochester, Minnesota during the period of 1945 to 1959, yielded an age-adjusted rate of 131 per 100,000 person-years.

The typical course of an $\mathrm{HZ}$ infection can be broken into three stages: prodromal, acute and chronic. During the prodromal stage of HZ, which occurs one to four days before the skin lesions, patients frequently have burning or stabbing pain that is sometimes accompanied by fever, malaise and headaches (5). The acute phase lasts seven to 10 days and is characterized by the cutaneous eruption of erythematous patches that coalesce to form vesicles that pustulate and crust over. This typically affects one or two adjacent dermatomes, with thoracic involvement being the most common (approximately $50 \%$ of patients with HZ); cervical and ophthalmic dermatomes are also commonly affected (approximately $10 \%$ of patients with HZ each) (4). Pain is the most frequent cause of acute and chronic morbidity in patients with HZ (5). Pain associated with the acute phase is usually self limiting, lasting two to three weeks (1), and the skin lesions usually heal within three weeks of rash onset (6). Complications are rare in immunocompetent patients $(3,6)$. Sequelae of $\mathrm{HZ}$ include neuralgia, cranial nerve palsies, myelitis, encephalitis, skin superinfection, cerebrovascular thrombosis, aseptic meningitis and ocular manifestations such as uveitis (7).

Postherpetic neuralgia (PHN) is the most common complication of HZ infection in immunocompetent patients (4). Those affected are typically elderly patients. They may suffer from spontaneous, sharp, stabbing, burning or throbbing pain; allodynia (pain in response to a stimulus that does not normally provoke pain); and altered sensory function (6).

\section{PHN}

There is no universally accepted definition of PHN. Some of the more common definitions include pain that persists after rash healing, pain that is present 30 days after rash appearance and pain that persists for more than three months after the first appearance of the rash (8). The International Association for the Study of Pain defines PHN as chronic pain with skin changes in the distribution of one or more roots of a nerve subsequent to acute HZ. The lack of consensus on the definition of PHN is responsible for prevalence estimates that range from $9 \%$ to $34 \%$ (6). Approximately $10 \%$ of patients with acute $\mathrm{HZ}$ have pain at one month, $5 \%$ at three months and 3\% at 12 months (9). de Moragas and Kierland
(10) found that PHN is uncommon in patients younger than 40 years of age. However, $65 \%$ of patients older than 60 years of age and $75 \%$ of patients older than 70 years of age have pain of at least one month's duration following rash healing.

Dworkin and Portenoy (6) identified a number of risk factors of PHN. These include age of onset, severity of the skin rash, severity of the acute pain, degree of the immune response, sensory dysfunction, fever and prodromal pain. They speculated that the risk factors are manifestations of a more severe infection. The risk of developing PHN is not increased in immunocompromised patients (11).

$\mathrm{VZV}$ is controlled mainly through cell-mediated immune mechanisms (1). It is believed that the waning of cellular immunity to the virus with advancing age or an immunocompromised state is associated with viral reactivation (11). For example, the incidence of $\mathrm{HZ}$ is increased among patients with lymphoproliferative malignancies, patients undergoing immunosuppressive therapy and patients with human immunodeficiency virus (1).

All modalities of sensory function, including perception of thermal, tactile, pinprick and vibratory sensations, appear to be diminished in PHN (12). PHN exhibits autonomic instability, ie, its intensity is exacerbated by physical and emotional stresses and alleviated by relaxation (13).

\section{MECHANISMS OF PAIN IN PHN}

Pain associated with acute HZ and PHN is considered neuropathic in nature. It was once thought that PHN was merely a continuation of the acute $\mathrm{HZ}$ pain. It is now believed that PHN is caused by a fundamentally different process from that causing pain in acute HZ. Postmortem studies (14) have shown dorsal horn atrophy and pathological changes in the sensory ganglion on the affected side in patients with PHN but not in patients with a history of HZ whose pain did not persist. While the mechanisms producing pain in PHN are not fully understood, injury to the peripheral nerves and spinal neurons, and altered central nervous system (CNS) signal processing are all thought to be important (11).

During acute HZ, viral replication causes tissue damage, which excites and sensitizes nociceptors. PHN may occur in part due to these sensitized nociceptors failing to return to normal after the acute inflammatory response has subsided. In addition, as the damaged afferent fibres attempt to reinnervate their original target organs, some become trapped in neuromas, and these nerve endings are spontaneously active. Studies suggest that there is an abnormal persistence of nociceptor-evoked central hyperexcitability. This state of central hyperexcitability is a normal reaction to injury, where the transmission of impulses down unmyelinated $\mathrm{C}$ fibres, carrying information from nociceptors, causes the second order spinal neuron to become spontaneously active and show exaggerated responses to any input. The source of this persistent, low level nociceptor input has yet to be identified. Glutaminergic synapses of the $N$-methyl-D-aspartate (NMDA) type play an important role in the process. There may also be a persistent inflammatory response within the spinal cord due to the virus (15). 
Evidence suggests that A-beta fibres - large, myelinated sensory fibres, carrying information from low threshold mechanoreceptors that are responsible for generating innocuous tactile sensations - play a large role in chronic pain. Damage to the peripheral nerve by $\mathrm{HZ}$ results in a number of atrophic and regenerative changes. In the process of reinnervating its original target organ, a number of growth factors are expressed. These factors promote growth on the peripheral and central ends of the fibre. It is believed that the regenerating A-beta fibres grow from their normal terminal area in the dorsal horn into the areas of the dorsal horn normally associated with nociceptors. This can lead to abnormal signal generation in response to innocuous stimuli, leading to allodynia. Other mechanisms that likely play a role in chronic pain include the removal of descending central inhibition on the dorsal horn neurons, making them more sensitive to low threshold, stimuli and the convergence of large and small fibres on wide dynamic range neurons in the dorsal horn that have become sensitized by nerve injury (16).

\section{TREATMENT MODALITIES FOR PHN}

The major problem in treating PHN is that, while there is a multitude of modalities available, none is very effective. The evaluation of which uncontrolled treatments are effective for PHN is difficult due to the tendency for VZV-associated pain to resolve over time $(9,17)$. This is a major confounding factor in any uncontrolled clinical trial designed to study a modality's efficacy; well designed studies must carefully define a group of patients whose pain is fairly stable to minimize this factor (9).

Acetylsalicylic acid and other simple analgesics: The mechanism of action of the nonsteroidal anti-inflammatory drugs (NSAIDs), is to prevent the production of prostaglandins, which are known sensitizers of nociceptors. Because PHN is a neuropathic pain, simple analgesics such as acetylsalicylic acid (ASA) are of limited value (11).

Tricyclic antidepressants: Tricyclic antidepressants (TCA) are one of the most commonly used treatment modalities for PHN. Amitriptyline (Elavil, Merck Sharp \& Dohm Canada, Kirkland, Quebec) is the prototypical TCA used to treat PHN. Initially it was thought that amitriptyline relieved PHN by alleviating the depressive symptoms patients experienced. However, pain relief is achieved at a lower dose than that used to treat depression (9). The major side effects of amitriptyline, which usually manifest at doses higher than those used for pain relief, are dry mouth, constipation, urinary retention, sedation, orthostatic hypotension, weight gain and arrhythmias (18).

By inhibiting the reuptake of serotonin and noradrenaline, amitriptyline may influence descending pathways involved in nociceptive pain modulation (18). It is possible that amitriptyline also acts under another mechanism because amitriptyline has recently been shown to inhibit central NMDA receptors, which are important in mediating central hyperexcitability. Amitriptyline may also block activated sodium channels and thus suppress ectopic activity in the CNS (18).
McQuay et al (19) systematically reviewed the efficacy of antidepressants in neuropathic pain. Three randomized, placebo controlled studies (20-22) on PHN, two involving amitriptyline and one involving desipramine, were included in this analysis. They found the odds ratio of the pooled data to be 6.8 (3.4 to 14.3), with a number needed to treat (NNT the number of patients needed to be treated to prevent one event) of 2.3 (1.7 to 3.3), where pain relief was greater than $50 \%$. In other words, they found the medication efficacious. In the three studies combined, 43 of the 77 (56\%) patients in the treatment group showed improvement.

Watson et al (23) demonstrated in a randomized, controlled trial that amitriptyline and nortriptyline appear to have similar analgesic effects in PHN.

Opioid analgesics: The use of opioid analgesics in chronic noncancer pain has been controversial. The conventional thinking for many years was that opioid analgesics were not effective for neuropathic pain syndromes (24). While opioid analgesics are the most effective class of therapeutic agents for pain, patients and physicians fear its dependence, addiction and tolerance potential (24). A growing body of evidence suggests that opioid analgesics may provide pain relief to patients with PHN. In the study by Pappagallo and Campbell (25), twenty patients with PHN were started on either controlled release oral morphine or slow release oxycodone in an open label study, and the doses were adjusted upwards until pain relief or intolerable side effects occurred. Eighteen patients reported some pain relief at six months' follow-up, with two reporting spontaneous resolution of the pain, five reporting excellent pain relief, nine reporting good pain relief and two reporting slight to moderate pain relief. Watson and Babul (26) demonstrated reduction in daily pain scores and weekly pain scores for steady pain, brief pain and allodynia with controlled release oxycodone in a randomized, controlled trial. Dellemijn and Vanneste (27) demonstrated that intravenous fentanyl reduces pain intensity and unpleasantness in a double-blind, placebo controlled crossover trial compared with diazepam or saline in 53 patients with neuropathic pain. Furthermore, Dellemijn et al (28) showed long term (12 weeks) transdermal fentanyl may be effective in noncancer neuropathic pain.

Other oral medications: Anticonvulsants can reduce the lancinating component of neuropathic pain (29). It is believed that these drugs stabilize the cell membrane, thus preventing the ectopic discharges responsible for the sharp lancinating pains. There has been only one randomized, clinical trial evaluating carbamazepine in PHN. In this trial by Gerson et al (30), a combination of carbamazepine and clomipramine was compared with transcutaneous electrical nerve stimulation (TENS), and the former was found to be superior. However, Volmink et al (31) noted in their review that the study had a number of methodological shortcomings; therefore, the results are hard to interpret. Side effects of carbamazepine include drowsiness, vertigo, blurred vision, nausea and vomiting, and hematological reactions (32).

Only one clinical trial assessing the efficacy of gabapentin in PHN has been published. Rowbotham et al (33) found in a 


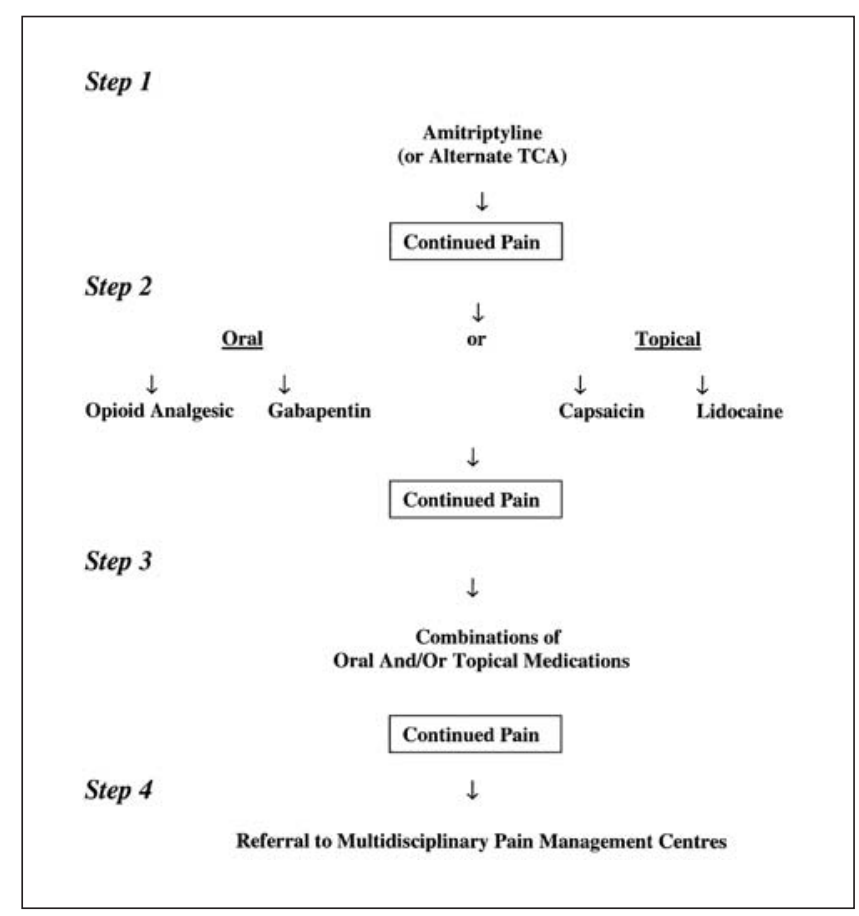

Figure 1) Postherpetic neuralgia treatment algorithm. TCA Tricylic antidepressants

double-blinded, placebo controlled trial involving 229 patients that gabapentin significantly reduced pain scores, and improved general well being and sleep scores. Similar to the TCAs, gabapentin only provided relief for about half of the patients $-61 \%$ of patients on the active medication reported minimally, moderately or much improved pain relief. Gabapentin is generally well tolerated, with the main side effects being somnolence, dizziness, ataxia and fatigue $(32,33)$. These side effects usually resolve on continued treatment (32).

Topical medications: Capsaicin cream (Zostrix, Medicus Canada Ltd, St Laurent, Quebec) is the only drug approved by the United States Food and Drug Administration for treatment of PHN (11). Capsaicin works by depleting substance P from terminals of $\mathrm{C}$ fibres, which carry pain information. Initially, capsaicin elicits a burning sensation that is intolerable for up to one-third of patients (11). Repeated exposure to capsaicin results in a long lasting analgesic effect (34).

Of three studies comparing capsaicin with either vehicle or placebo, two found capsaicin to provide statistically significant pain relief. The trials by Bernstein et al (35) and Watson et al (36), when pooled, yielded a statistically significant benefit and an NNT of 3.4. In the pooled data of the two above mentioned studies, only 50 of 90 patients $(55 \%)$ on the active medication showed improvement.

In one of the few other randomized, placebo controlled studies on topical medications for PHN, Rowbotham et al (37) found that lidocaine patches provided statistically significant pain relief. This study showed that 24 of the 35 patients who tried the patch had some pain relief. An earlier, uncontrolled study by Stow et al (38) showed that 5\% lidocaine/prilocaine cream provided relief for all 12 patients with
PHN $6 \mathrm{~h}$ after application. Overall, the probable efficacy of topical medications for PHN and evidence in support of capsaicin as an effective treatment modality are limited.

Physical modalities: There has only been one trial by Lewith et al (39) investigating the efficacy of acupuncture on PHN. This study, using auricular acupuncture, showed no significant benefit. In a review of all double-blinded, randomized trials on acupuncture done to relieve chronic pain, ter Riet et al (40) found that the studies were, in general, poorly done and that even the better designed studies showed contradictory evidence. The problems with studies on acupuncture are the lack of blinding and the lack of a suitable placebo.

There is not much evidence to support the use of TENS in PHN. In one study by Nathan and Wall (41), TENS was found to be useful in 16 of 30 patients with PHN, but they were not able to conclude that TENS was effective enough to warrant its routine use.

Nerve blocks: There have been no randomized, controlled trials involving the efficacy of nerve blocks (eg, stellate ganglion blocks, epidural or intrathecal injections of steroids, or paravertebral sympathetic blocks) with respect to PHN. Most studies have looked at the ability of nerve blocks to prevent PHN. However, there are a few case reports and uncontrolled studies (42-46) that suggest how effective injection techniques are. One study by Milligan and Nash (44) of 77 cases of PHN showed that of the 42 patients who received stellate ganglion blocks, 30 (71\%) showed some improvement. They also noticed that the benefit of the stellate ganglion block was most pronounced when given to patients whose symptoms had lasted less than one year. Kikuchi et al (45) demonstrated that $90 \%$ of patients experienced satisfactory analgesia 24 weeks after injection of lidocaine and methylprednisolone acetate intrathecally but not epidurally.

\section{PREVENTION OF PHN}

Because PHN is difficult to treat, it makes sense to prevent PHN from occurring in the first place. A number of strategies have been suggested for prevention, including oral antiviral medications, corticosteroids and nerve blocks.

Most patients receive antiviral medications such as acyclovir or famciclovir during their acute attack of HZ. The standard treatment has been $800 \mathrm{mg} /$ day of oral acyclovir administered within $72 \mathrm{~h}$ of rash onset. A number of studies (47-49) have shown that these medications, if administered within $72 \mathrm{~h}$ of rash onset, are able to relieve the early signs and symptoms of acute $\mathrm{HZ}$ and reduce scarring. The clinical benefit in a meta-analysis of the acyclovir trials by Jackson et al (50) was small, with a short reduction in rash duration and a decrease in pain at six months of $44 \%$ in immunocompetent adults. Thus, physicians must balance the cost and possible side effects of a seven- to 10-day course of an antiviral medication against the potentially considerable costs of pain and treatment of PHN.

There is ongoing debate as to whether antivirals are able to reduce significantly the incidence of PHN or shorten the duration of zoster-associated pain. In the largest trial studying acyclovir and HZ, McKendrick et al (51) found no difference 
between acyclovir and placebo in either the incidence or the duration of PHN. However, Wood et al (52), in their metaanalysis of four double-blinded, randomized, placebo controlled studies, showed that acyclovir accelerated pain resolution. One study of famciclovir, at both $500 \mathrm{mg}$ or $750 \mathrm{mg}$, by Tyring et al (48), showed a statistically significant reduction in the length of PHN by one-half compared with placebo.

\section{CONCLUSIONS}

PHN is a difficult condition to treat. Some evidence exists in support of the efficacy of the various treatment modalities. Analgesics such as ASA and NSAIDs are of limited value. The TCAs have the most evidence supporting their role in treating PHN, although there is benefit for only half of the patients. Opioids appear to be effective analgesics, although studies are limited. Carbamazepine has not been demon-

\section{REFERENCES}

1. Arvin AM. Varicella-zoster virus: overview and clinical manifestations. Semin Dermatol 1996;15:4-7.

2. Hope-Simpson RE. The nature of herpes zoster: A long-term study and a new hypothesis. Proc R Soc Med 1965;58:9-20.

3. Donahue JG, Choo PW, Manson JE, Platt R. The incidence of herpes zoster. Arch Intern Med 1995;155:1605-9.

4. Ragozzino MW, Melton LJ III, Kurland LT, Chu CP, Perry HO. Population-based study of herpes zoster and its sequelae. Medicine 1982;61:310-6.

5. Straus SE, Ostrove JM, Inchauspe G, et al. NIH conference. Varicella-zoster virus infections. Biology, natural history, treatment, and prevention. Ann Intern Med 1988;108:221-37.

6. Dworkin RH, Portenoy RK. Pain and its persistence in herpes zoster. Pain 1996;67:241-51.

7. Choo PW, Galil K, Donahue JG, Walker AM, Spiegelman D, Platt R. Risk factors for postherpetic neuralgia. Arch Intern Med 1997; 157:1217-24.

8. Johnson RW. Herpes zoster and postherpetic nerualgia. Optimal treatment. Drugs Aging 1997;10:80-94

9. Watson CP. The treatment of postherpetic neuralgia. Neurology 1995;45:S58-60.

10. de Moragas JM, Kierland RR. The outcome of patients with herpes zoster. AMA Arch Dermatol 1957;75:193-96.

11. Kost RG, Straus SE. Postherpetic neuralgia - pathogenesis, treatment, and prevention. N Engl J Med 1996;335:32-42.

12. Nurmikko T. Clinical features and pathophysiologic mechanisms of postherpetic neuralgia. Neurology 1995;45(Suppl 8):S54-5.

13. Bowsher D. Pathophysiology of postherpetic neuralgia: towards a rational treatment. Neurology 1995;45(Suppl 8):S56-7.

14. Watson CP, Deck JH, Morshead C, Van der Kooy D, Evans RJ. Post-herpetic neuralgia: further post-mortem studies of cases with and without pain. Pain 1991;44:105-17

15. Bennett GJ. Hypotheses on the pathogenesis of herpes zoster associated pain. Ann Neurol 1994;35(Suppl):S38-41.

16. Woolf CJ, Doubell TB. The pathophysiology of chronic pain increased sensitivity to low threshold A beta-fiber inputs. Curr Opin Neurobiol 1994;4:525-34.

17. Wood MJ, Ogan PH, McKendrick MW, Care CD, McGill JI, Webb EM. Efficacy of oral acyclovir treatment of acute herpes zoster. Am J Med 1988;85:79-83.

18. Bryson HM, Wilde MI. Amitriptyline. A review of its pharmacological properties and therapeutic use in chronic pain states. Drugs Aging 1996;8:459-76.

19. McQuay HJ, Tramer M, Nye BA, Carroll D, Wiffen PJ, Moore RA. A systematic review of antidepressants in neuropathic pain. Pain 1996;68:217-27. strated to be effective in treating PHN. Gabapentin is the newest drug used for the treatment of PHN, and while one large trial has suggested its efficacy, further studies are needed. Physical modalities such as TENS and acupuncture, and topical medications such as capsaicin and lidocaine, are probably most useful as adjuncts to centrally acting agents, not as a primary treatment modality. Anecdotally, nerve blocks are effective in relieving PHN, although there are no controlled clinical trials showing efficacy. An algorithm of recommendations for the treatment of PHN is shown in Figure 1.

ACKNOWLEDGMENT: The authors thank Dr Ian Beauprie for reviewing this paper and Ms Sylvia Redmond for manuscript preparation.

20. Max MB, Schafer SC, Culnane M, Smoller B, Dubner R, Gracely RH. Amitriptyline, but not lorazepam, relieves postherpetic neuralgia. Neurology 1988;38:1427-32.

21. Watson CP, Evans RJ, Reed K, Merskey H, Goldsmith L, Warsh J. Amitriptyline versus placebo in postherpetic neuralgia. Neurology 1982;32:671-3.

22. Kishore-Kumar R, Max MB, Schafer SC, et al. Desipramine relieves postherpetic neuralgia. Clin Pharmacol Ther 1990;47:305-12.

23. Watson CP, Vernich L, Chipman M, Reed K. Nortriptyline versus amitriptyline in postherpetic neuralgia: a randomized trial. Neurology 1998;51:1166-71

24. Rowbotham MC. Managing post-herpetic neuralgia with opioids and local anesthetics. Ann Neurol 1994;35:S46-9.

25. Pappagallo M, Campbell JN. Chronic opioid therapy as alternative treatment for post-herpetic neuralgia. Ann Neurol 1994;35(Suppl):S54-6.

26. Watson $\mathrm{CP}$, Babul N. Efficacy of oxycodone in neuropathic pain: a randomized trial in postherpetic neuralgia. Neurology 1998;50:1837-41.

27. Dellemijn PL, Vanneste JA. Randomised double-blind active-placebo-controlled crossover trial of intravenous fentanyl in neuropathic pain. Lancet 1997;349:753-8.

28. Dellemijn PL, van Duijn H, Vanneste JA. Prolonged treatment with transdermal fentanyl in neuropathic pain. J Pain Symptom Manage 1998;16:220-9.

29. Swerdlow M. Anticonvulsant drugs and chronic pain. Clin Neuropharmacol 1984;7:51-82.

30. Gerson GR, Jones RB, Luscombe DK. Studies on the concomitant use of carbamazepine and clomipramine for the relief of post-herpetic neuralgia. Postgrad Med J 1977;53:104-9.

31. Volmink J, Lancaster T, Gray S, Silagy C. Treatments for postherpetic neuralgia - a systematic review of randomized controlled trials. Fam Pract 1996;13:84-91.

32. McNamara JO. Drugs effective in the therapy of the epilepsies. In: Hardman JG, Limbird LE, eds. Goodman and Gilman's the Pharmacological Basis of Therapeutics, 9th edn. New York: McGraw-Hill, 1996.

33. Rowbotham M, Harden N, Stacey B, Bernstein P, Magnus-Miller L. Gabapentin for the treatment of postherpetic neuralgia: a randomized controlled trial. JAMA 1998;280:1837-42.

34. Rains C, Bryson HM. Topical capsaicin. A review of its pharmacological properties and therapeutic potential in post-herpetic neuralgia, diabetic neuropathy and osteoarthritis. Drugs Aging 1995;7:317-28.

35. Bernstein JE, Korman NJ, Bickers DR, Dahl MV, Millikan LE. 
Topical capsaicin treatment of chronic postherpetic neuralgia. J Am Acad Dermatol 1989;21:265-70.

36. Watson CP, Tyler KL, Bickers DR, Millikan LE, Smith S, Coleman E. A randomized vehicle-controlled trial of topical capsaicin in the treatment of postherpetic neuralgia. Clin Ther 1993;15:510-26.

37. Rowbotham MC, Davies PS, Verkempinck C, Galer BS. Lidocaine patch: double-blind controlled study of a new treatment method for post-herpetic neuralgia. Pain 1996;65:39-44.

38. Stow PJ, Glynn CJ, Minor B. EMLA cream in the treatment of post-herpetic neuralgia. Efficacy and pharmacokinetic profile. Pain 1989;39:301-5.

39. Lewith GT, Field J, Machin D. Acupuncture compared with placebo in post-herpetic pain. Pain 1983;17:361-8.

40. ter Riet G, Kleijnen J, Knipschild P. Acupuncture and chronic pain; a criteria-based meta-analysis. J Clin Epidemiol 1990;43:1191-9.

41. Nathan PW, Wall PD. Treatment of post-herpetic neuralgia by prolonged electric stimulation. Br Med J 1974;3:645-7.

42. Fine PG, Ashburn MA. Effect of stellate ganglion block with fentanyl on postherpetic neuralgia with a sympathetic component. Anesth Analg 1988;67:897-9.

43. Takeda T, Iida H, Ohta S, et al. [Two elderly patients with thoracic herpetic pain and post herpetic neuralgia treated with continuous thoracic sympathetic ganglion block through a placed catheter]. Masui 1998;47:346-9.
44. Milligan NS, Nash TP. Treatment of post-herpetic neuralgia. A review of 77 consecutive cases. Pain 1985;23:381-6.

45. Kikuchi A, Kotani N, Sato T, Takamura, Sakai I, Matsuki A. Comparative therapeutic evaluation of intrathecal versus epidural methylprednisolone for long-term analgesia in patients with intractable postherpetic neuralgia. Reg Anesth Pain Med 1999;24:287-93.

46. Perkins HM, Hanlon PR. Epidural injection of local anesthetic and steroids for relief of pain secondary to herpes zoster. Arch Surg 1978;113:253-4.

47. Huff JC. Oral acyclovir therapy of acute herpes zoster: a multicenter study. Res Clin Forums 1987;9:37-45.

48. Tyring S, Barbarash RA, Nahlik JE, et al. Famciclovir for the treatment of acute herpes zoster: effects on acute disease and postherpetic neuralgia. A randomized, double-blind, placebo controlled trial. Ann Intern Med 1995;123:89-96.

49. McKendrick MW, McGill JI, White JE, Wood MJ. Oral acyclovir in acute herpes zoster. Br Med J 1986;293:1529-32.

50. Jackson JL, Gibbons R, Meyer G, Inouye L. The effect of treating herpes zoster with oral acyclovir in preventing postherpetic neuralgia. A meta-analysis. Arch Intern Med 1997;157:909-12.

51. McKendrick MW. McGill JI. Wood MJ. Lack of effect of acyclovir on postherpetic neuralgia. Br Med J 1989;298:431.

52. Wood MJ, Kay R, Dworkin RH, Soong SJ, Whitley RJ. Oral acyclovir therapy accelerates pain resolution in patients with herpes zoster: a meta-analysis of placebo-controlled trials. Clin Infect Dis 1996;22:341-7. 


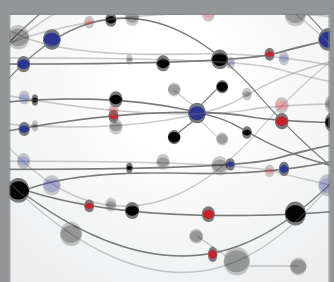

The Scientific World Journal
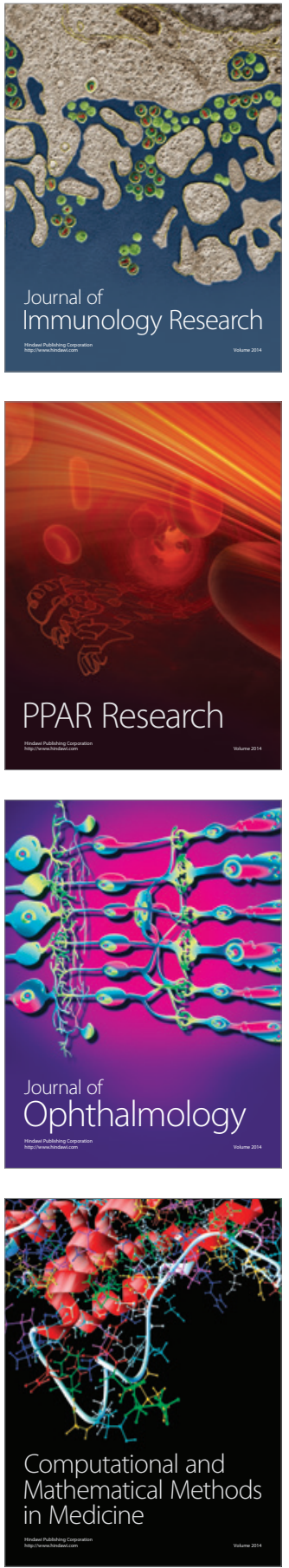

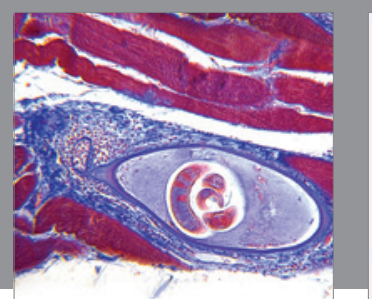

Gastroenterology Research and Practice

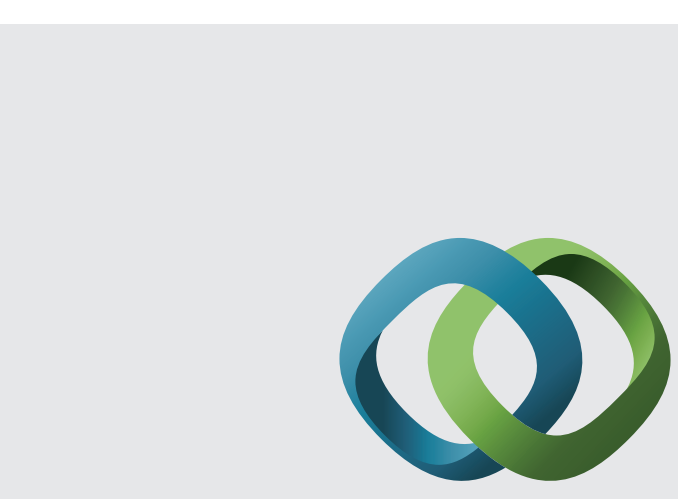

\section{Hindawi}

Submit your manuscripts at

http://www.hindawi.com
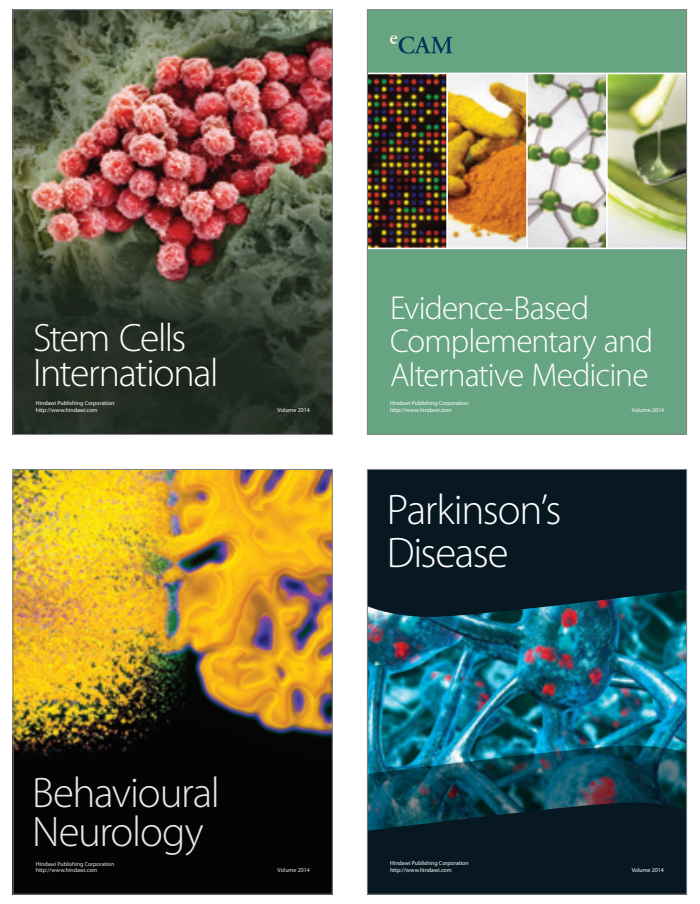
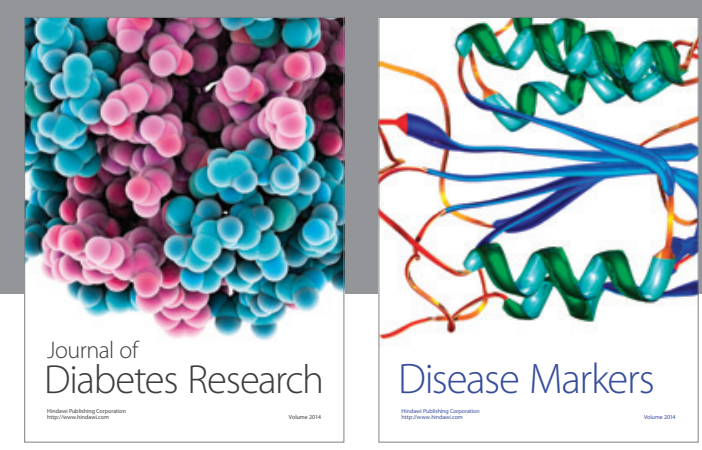

Disease Markers
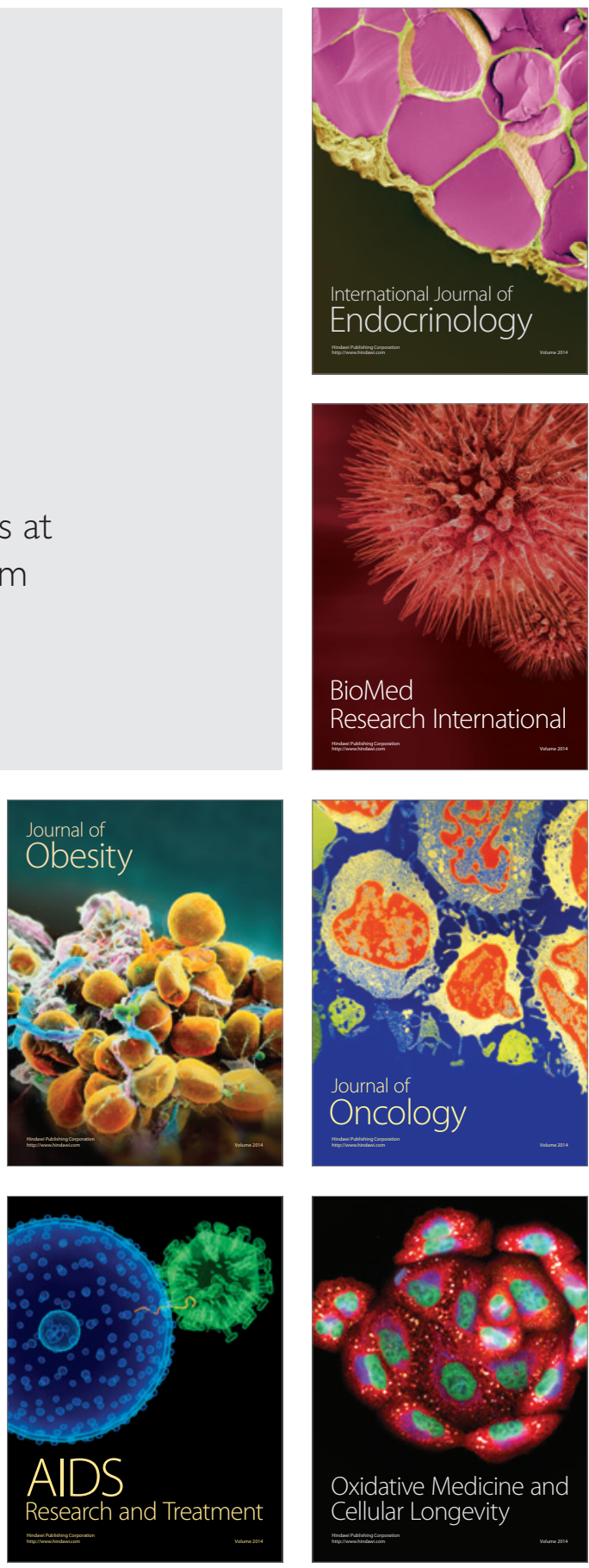